\title{
Hair-Thread Tourniquet Syndrome
}

Murat Türkarslan, Yunsur Çevik, Tuba Şafak, Emine Emektar

Clinic of Emergency Medicine, Keçiören Training and Research Hospital, Ankara, Turkey

A 3-month-old boy presented to our emergency department after 3 days of restlessness, erythema, and swelling on his left third and fourth toes, which was detected by his mother while changing his diaper. Physical examinations revealed hyperemia, edema, and tenderness with a strangulation ring at the proximal part of the third and fourth toes, and the skin of the fourth toe was cut. On examination using magnification, several tightly eight-shaped entangled hair fibers were found (Figure 1a, b). The hair fibers were gently removed. Hyperemia and edema regressed after a 2-h observation period. The patient was discharged home with topical antibiotic treatment.

Hair-thread tourniquet syndrome is a rare but dangerous disorder if early treatment is not provided. It is frequently reported in fingers, toes, and external genitalia in 6-36-week-old babies (1). Edema caused by constriction blocks arterial and venous circulation. If treat- ment delays tissue necrosis and auto-amputation can develop at the affected area. Although the mechanism underlying thread wrapping is not clearly defined, it is thought to be accidental or a combination of babies' plantar flexion behavior and overall clothing (2). The treatment strategy simply involves incision and removal of hair fibers (3). If the hair fiber cuts the skin and becomes invisible, surgical exploration should be necessary.

\section{References}

1. CevikY, Kavalci C. Hair tourniquet syndrome. Ann Saudi Med 2010; 30:416-7. [CrossRef]

2. Barton DJ, Sloan GM, Nichter LS, Reinisch JF. Hair-thread tourniquet syndrome. Pediatrics 1988; 82: 925-8.

3. Serour F, Gorenstein A. Treatment of the toe tourniquet syndrome in infants. Pediatr Surg Int 2003; 19: 598-600. [CrossRef]

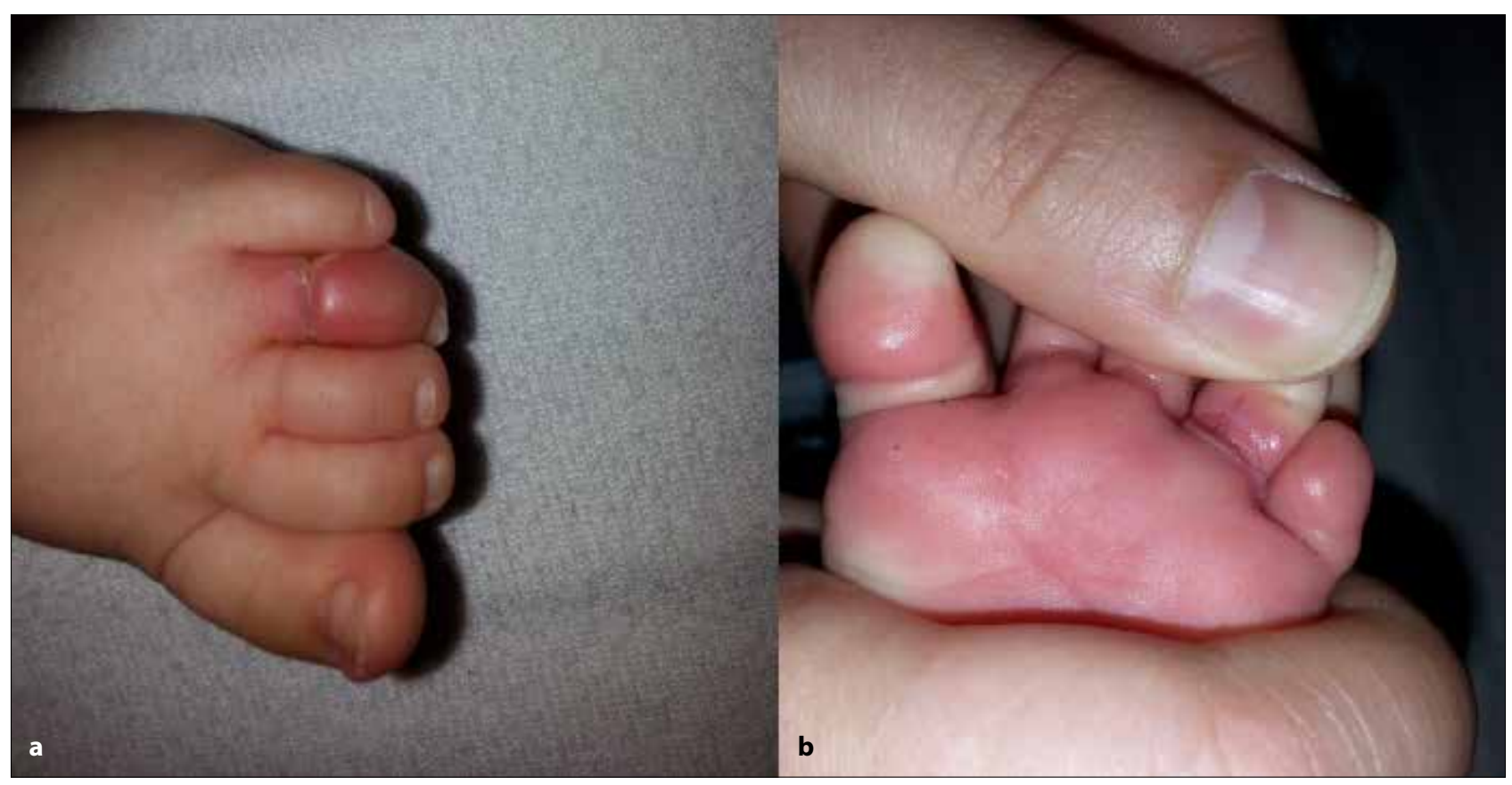

Figure 1. a, b. Views from different angles of the eight-shaped hair fiber entangled on the $3^{\text {rd }}$ and $4^{\text {th }}$ toes 